\title{
Usability Test Results for Encore in an Academic Library
}

Megan Johnson

ABSTRACT

This case study gives the results a usability study for the discovery tool Encore Synergy, an Innovative Interfaces product, launched at Appalachian State University Belk Library \& Information Commons in January 2013. Nine of the thirteen participants in the study rated the discovery tool as more user friendly, according to a SUS (Standard Usability Scale) score, than the library's tabbed search layout, which separated the articles and catalog search. All of the study's participants were in favor of switching the interface to the new "one box" search. Several glitches in the implementation were noted and reported to the vendor. The study results have helped develop Belk library training materials and curricula. The study will also serve as a benchmark for further usability testing of Encore and Appalachian State Library's website. This article will be of interest to libraries using Encore Discovery Service, investigating discovery tools, or performing usability studies of other discovery services.

\section{INTRODUCTION}

Appalachian State University's Belk Library \& Information Commons is constantly striving to make access to libraries resources seamless and simple for patrons to use. The library's technology services team has conducted usability studies since 2004 to inform decision making for iterative improvements.

The most recent versions (since 2008) of the library's website have featured a tabbed layout for the main search box. This tabbed layout has gone through several iterations and a move to a new Content Management System (Drupal). During fall semester 2012, the library website's tabs were: Books \& Media, Articles, Google Scholar, and Site Search (see figure 1). Some issues with this layout, documented in earlier usability studies and through anecdotal experience, will be familiar to other libraries who have tested a tabbed website interface. User access issues include the belief of many patrons that the "articles" tab looked for all articles the library had access to. In reality the "articles" tab searched seven EBSCO databases. Belk Library has access to over 400 databases. Another problem noted with the tabbed layout was that patrons often started typing in the articles box, even when they knew they were looking for a book or DVD. This is understandable, since when most of us see a search box we just start typing, we do not read all the information on the page.

Megan Johnson (johnsnm@appstate.edu) is E-Learning and Outreach Librarian, Belk Library and Information Commons, Appalachian State University, Boone, NC. 


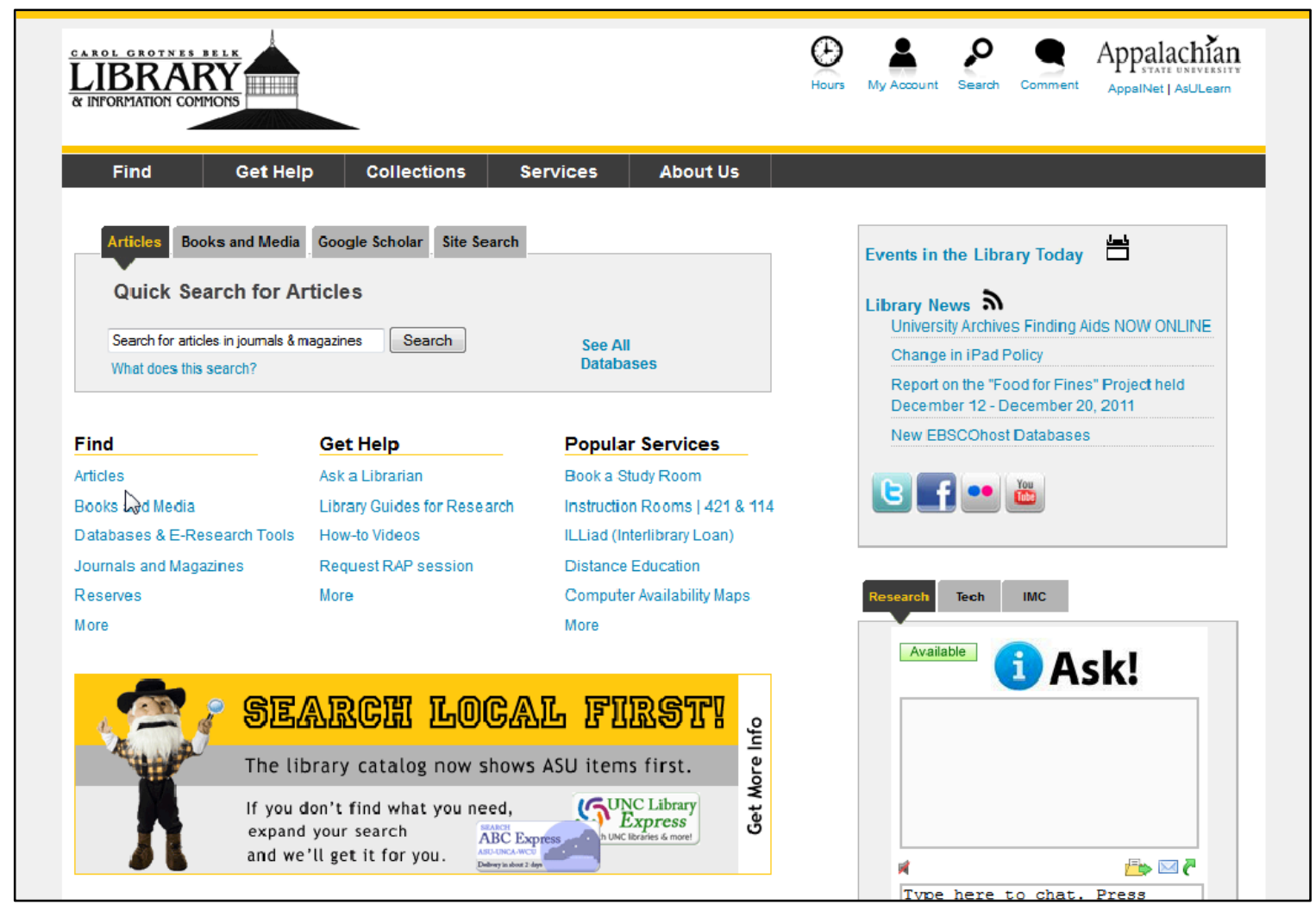

Figure 1. Appalachian State University Belk Library website tabbed layout search, December 2012.

A third documented user issue is confusion over finding an article citation. This is a rather complex problem, since it has been demonstrated through assessment of student learning that many students cannot identify the parts of a citation, so this usability issue goes beyond the patron being able navigate the library's interface, it is partly a lack of information literacy skills. However, even sophisticated users can have difficulty in determining if the library owns a particular journal article. This is an ongoing interface problem for Belk Library and many other academic libraries. Google Scholar (GS) often works well for users with a journal citation, since on campus they can often simply copy and paste a citation to see if the library has access, and, if so, the full text it is often is available in a click or two. However, if there are no results found using GS, the patrons are still not certain if the library owns the item.

\section{BACKGROUND}

In 2010, the library formed a task force to research the emerging market of discovery services. The task force examined Summon, EBSCO Discovery Service, Primo and Encore Synergy and found the products, at that time, to still be immature and lacking value.

In April 2012, the library reexamined the discovery market and conducted a small benchmarking usability study (the results are discussed in the methodology section and summarized in appendix A). The library felt enough improvements had been made to Innovative Interface's Encore 
Synergy product to justify purchasing this discovery service. An Encore Synergy Implementation Working Group was formed, and several subcommittees were created, including end-user preferences, setup \& access, training, and marketing. To help inform the decision of these subcommittees, the author conducted a usability study in December 2012, which was based on, and expanded upon, the April 2012 study.

The goal of this study was to test users' experience and satisfaction with the current tabbed layout, in contrast to the "one box" Encore interface. The library had committed to implementing Encore Synergy, but there are options in layout of the search box on the library's homepage. If users expressed a strong preference for tabs, the library could choose to leave a tabbed layout for access to the articles part of Encore, for the catalog part, and create tabs for other options like Google Scholar, and a search of the library's website. A second goal of the study was to benchmark the user experience for the implementation of Encore synergy so that, over time, improvements could be made to promote seamless access to Appalachian State University library's resources. A third goal of this study was to document problems users encountered and report them to Innovative.

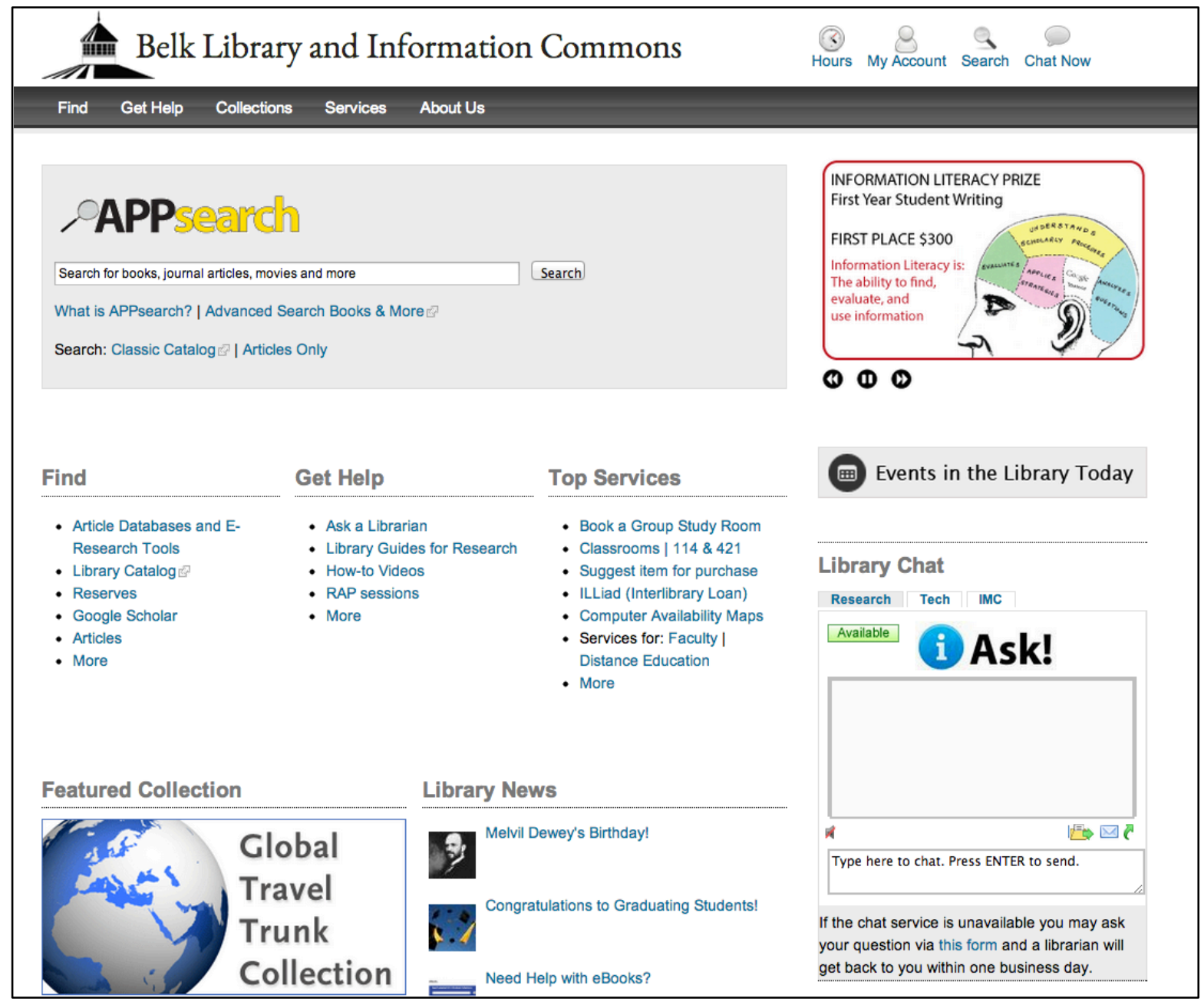

Figure 2. Appalachian State University Belk Library website Encore Search, January 2013. 


\section{LITERATURE REVIEW}

There have been several recent reviews of the literature on library discovery services. ThomsettScott and Reese conclude that discovery tools are a mixed blessing. ${ }^{1}$ Users can easily search across abroad areas of library resources and limiting by facets is helpful. Downsides include loss of individual database specificity and user willingness to look beyond the first page of results. Longstanding library interface problems, such as patrons' lack of understanding of holding statements, and knowing when to it is appropriate to search in a discipline specific database are not solved by discovery tools. ${ }^{2}$

In a recent overview of discovery services, Hunter lists four vendors whose products have both a discovery layer and a central index: EBSCO's Discovery Service (EDS); Ex Libris' Primo Central Index; Serials Solutions' Summon; and OCLC's WorldCat Local (WCL). ${ }^{3}$ Encore does not have currently offer a central index or pre-harvested metadata for articles, so although Encore has some of the features of a discovery service, such as facets and connections to full text, it is important for libraries considering implementing Encore to understand that the part of Encore that searches for articles is a federated search. When Appalachian purchased Encore, not all the librarians and staff involved in the decision making were fully aware of how this would affect the user experience. Further discussion of this in the "glitches revealed" section.

Fagan et al. discuss James Madison University's implementation of EBSCO Discovery Service and their customizations of the tool. They review the literature of discovery tools in several areas, including articles that discuss the selection processes, features, and academic libraries' decisions process following selection. They conclude, the "literature illustrates a current need for more usability studies related to discovery tools." 4

The most relevant literature to this study are case studies documenting a library's experience with implementing a discovery services and task based usability studies of discovery services. Thomas and Buck ${ }^{5}$ sought to determine with a task based usability study whether users were as successful performing common catalog-related tasks in WorldCat Local (WCL) as they are in the library's current catalog, Innovative Interfaces' WebPAC. The study helped inform the library's decision, at that time, to not implement WCL.

Beecher and Schmidt 6 discuss American University's comparison of WCL and Aquabrowser (two discovery layers), which were implemented locally. The study focused on user preferences based on students "normal searching patterns" 7 rather than completion of a list of tasks. Their study revealed undergraduates generally preferred WCL, and upperclassmen and graduates tended to like Aquabrower better. Beecher and Schmidt discuss the research comparing assigned tasks versus user-defined searches, and report that a blend of these techniques can help researchers understand user behavior better. ${ }^{8}$ 
This article reports on a task-based study, in which the last question asks the participant to research something they had looked for within the past semester, and the results section indicates that the most meaningful feedback came from watching users research a topic they had a personal interest in. Having assigned tasks also can be very useful. For example, an early problem noted with discovery services was poor search results for specific searches on known items, such as the book "The Old Man and the Sea." Assigned tasks also give the user a chance to explore a system for a few searches, so when they search for a topic of personal interest, it is not their first experience with a new system. Blending assigned tasks with user tasks proved helpful in this study's outcomes.

Encore Synergy has not yet been the subject of a formally published task-based usability study. Allison reports on an analysis of Google Analytic statistics at University of Nebraska-Lincoln after Encore was implemented. ${ }^{9}$ The article concludes that Encore increases the user's exposure to all the library's holdings, describes some of the challenges UNL faced and gives recommendations for future usability studies to evaluate where additional improvements should be made. The article also states UNL plans to conduct future usability studies.

Although there are not yet formal published task-based studies on Encore, at least one blogger from Southern New Hampshire University documented their implementation of the service. Singley reported in 2011, "Encore Synergy does live up to its promise in presenting a familiar, user-friendly search environment. ${ }^{10}$ She points out, "To perform detailed article searches, users still need to link out to individual databases." This study confirms that users do not understand that articles are not fully indexed and integrated; articles remain, in Encore's terminology, in "database portfolios." See the results section, task 2 , for a fuller discussion of this topic.

\section{METHOD}

This study included a total of 13 participants. These included four faculty members, and six students recruited through a posting on the library's website offering participants a bookstore voucher. Three student employees were also subjects (these students work in the library's mailroom and received no special training on the library's website). For the purposes of this study, the input of undergraduate students, the largest target population of potential novice users, was of most interest. Table 3 lists demographic details of the student or faculty's college, and for students, their year.

This was a task-based study, where users were asked to find a known book item and follow two scenarios to find journal articles. The following four questions/tasks were handed to the users on a sheet of paper:

1. Find a copy of the book the Old Man and the Sea.

2. In your psychology class, your professor has assigned you a 5-page paper on the topic of eating disorders and teens. Find a scholarly article (or peer-reviewed) that explores the relation between anorexia and self-esteem. 
3. You are studying modern Chinese history and your professor has assigned you a paper on foreign relations. Find a journal article that discusses relations between China and the US.

4. What is a topic you have written about this year? Search for materials on this topic.

The follow up questions where verbally asked either after a task, or asked as prompts while the subject was working.

1. After the first task (find a copy of the book The Old Man and the Sea) when the user finds the book in APPsearch, ask:

"Would you know where to find this book in the library?"

2. How much of the library's holdings do you think APPsearch/ Articles Quick Search is looking across?

3. Does "peer reviewed" mean the same as "scholarly article"?

4. What does the "refine by tag" block the right mean to you?

5. If you had to advise the library to either stay with a tabbed layout, or move to the one search box, what would you recommend?

Participants were recorded using Techsmith's screen-casting software Camtasia, which allows the user's face to be recorded along with their actions on the computer screen. This allows the observer to not rely solely on notes or recall. If the user encounters a problem with the interface, having the session recorded makes it simple to create (or recreate) a clip to show the vendor. In the course of this study, several clips were sent to Innovative Interfaces, and they were responsive to many of the issues revealed. Further discussion is in the "glitches revealed" section.

Seven of the subjects first used the library site's tabbed layout (which was then the live site) as seen in figure 1. After they completed the tasks, participants filled in a System Usability Scale (SUS) form. The users then completed the same tasks on the development server using Encore Synergy. Participants next filled out a SUS form to reflect their impression of the new interface. Encore is locally branded as APPsearch and the terms are used interchangeably in this study.

The six other subjects started with the APPsearch interface on a development server, completed a SUS form, and then did the same tasks using the library's tabbed interface. The time it took to conduct the studies was ranged from fifteen to forty minutes per participant, depending on how verbal the subject was, and how much they wanted to share about their impressions and ideas for improvement.

Jakob Nielson has been quoted as saying you only need to test with five users: "After the fifth user, you are wasting your time by observing the same findings repeatedly but not learning much new."11 He argues for doing tests with a small number of users, making iterative improvements, and then retesting. This is certainly a valid and ideal approach if you have full control of the design. In the case of a vendor-controlled product, there are serious limitations to what the 
librarians can iteratively improve. The most librarians can do is suggest changes to the vendor, based on the results of studies and observations.

When evaluating discovery services in the spring of 2012, Appalachian State Libraries conducted a four person task based study (see Appendix A), which used University of Nebraska at Lincoln's implementation of Encore as a test site to benchmark our students' initial reaction to the product in comparison to the library's current tabbed layout. In this small study, the average SUS score for the library's current search box layout was 62, and for UNL's implementation of Encore, it was 49. This helped inform the decision of Belk Library, at that time, not to purchase Encore (or any other discovery service), since students did not appear to prefer them.

This paper reports on a study conducted in December 2012 that showed a marked improvement in users' gauge of satisfaction with Encore. Several factors could contribute to the improvement in SUS scores. First is the larger sample size of 13 compared to the earlier study with four participants. Another factor is in the April study, participants were using an external site they had no familiarity with, and a first experience with a new interface is not a reliable gauge of how someone will come to use the tool over time. This study was also more robust in that it added the task of asking the user to search for something they had researched recently and the follow up questions were more detailed. Overall it appears that, in this case, having more than four participants and a more robust design gave a better representation of user experience.

\section{The System Usability Scale (SUS)}

The System Usability Scale has been widely used in usability studies since its development in 1996. Many libraries use this tool in reporting usability results. ${ }^{12,13}$ It is simple to administer, score, and understand the results. ${ }^{14}$ SUS is an industry standard with references in over 600 publications. ${ }^{15}$ An "above average" score is 68. Scoring a scale involves a formula where odd items have one subtracted from the user response, and with even numbered items, the user response is subtracted from five. The total converted responses are added up, and then multiplied by 2.5. This makes the answers easily grasped on the familiar scale of 1-100. Due to the scoring method, it is possible that results are expressed with decimals. ${ }^{16} \mathrm{~A}$ sample SUS scale is included in Appendix D.

\section{RESULTS}

The average SUS score for the 13 users for Encore was 71.5, and for the tabbed layout, the average SUS score was 68. This small sample set indicates there was a user preference for the discovery service interface. In a relatively small study like this, these results do not imply a scientifically valid statistical measurement. As used in this study, the SUS scores are simply a way to benchmark how "usable" the participants rated the two interfaces.

When asked the subjective follow up question, "If you had to advise the library to either stay with a tabbed layout, or move to the one search box, what would you recommend?" $100 \%$ of the participants recommended the library change to APPsearch, (although four users actually rated 
the tabbed layout with a higher SUS score). These four participants said things along the lines of, "I can get used to anything you put up."

\begin{tabular}{|c|c|c|l|c|}
\hline Participant & $\begin{array}{c}\text { SUS } \\
\text { Encore }\end{array}$ & $\begin{array}{c}\text { SUS } \\
\text { Tabbed } \\
\text { layout }\end{array}$ & Year and major or College & $\begin{array}{l}\text { APPsearch } \\
\text { First }\end{array}$ \\
\hline Student A & 90 & 70 & Senior/Social Work/Female & No \\
\hline Student B & 95 & 57.5 & Freshman/Undeclared/Male & Yes \\
\hline Student C & 82.5 & 57.5 & Junior/English/Male & Yes \\
\hline Student D & 37.5 & 92 & $\begin{array}{l}\text { Sophomore/Actuarial } \\
\text { Science/Female }\end{array}$ \\
\hline Student E & 65 & 82.5 & Junior/Psychology/Female & Yes \\
\hline Student F & 65 & 77.5 & Senior/Sociology/Female & No \\
\hline Student G & 67.5 & 75 & Junior/Music Therapy/Female & No \\
\hline Student H & 90 & 82.5 & Senior/Dance/Female & No \\
\hline Student I & 60 & 32.5 & Senior/Political Science/Female & No \\
\hline Faculty A & 40 & 87.5 & Family \& Consumer/Science/Female & Yes \\
\hline Faculty B & 80 & 60 & English/Male & No \\
\hline Faculty C & 60 & 55 & Education/Male & No \\
\hline Faculty D & 97.5 & 57.5 & English/Male & Yes \\
\hline Average & $\mathbf{7 1 . 5}$ & $\mathbf{6 8}$ & & \\
\hline
\end{tabular}

Table 1. Demographic details and individual and average SUS scores.

\section{DISCUSSION}

\section{Task 1:}

"Find a copy of the book The Old Man and the Sea."

All thirteen users had faster success using Encore. When using Encore, this "known item" is in the top three results. Encore definitely performed better than the classic catalog in saving the time of the user.

In approaching task 1 from the tabbed layout interface, four out of thirteen users clicked on the books and media tab, changed the drop down search option to "title," and were (relatively) quickly successful. The remaining nine who switched to the books and media tab and used the default keyword search for "the old man and the sea" had to scan the results (using this search method, the book is the seventh result in the classic catalog), which took two users almost 50 seconds. This length of time, for an "average user" to find a well-known book is not considered to be acceptable to the technology services team at Appalachian State University.

When using the Encore interface, the follow up question for this task was, "would you know where to find this book in the library?" Nine out of 13 users did not know where the book would be, or 
how to find it. The three faculty members and student D could pick out the call number and felt they could locate the book in the stacks.

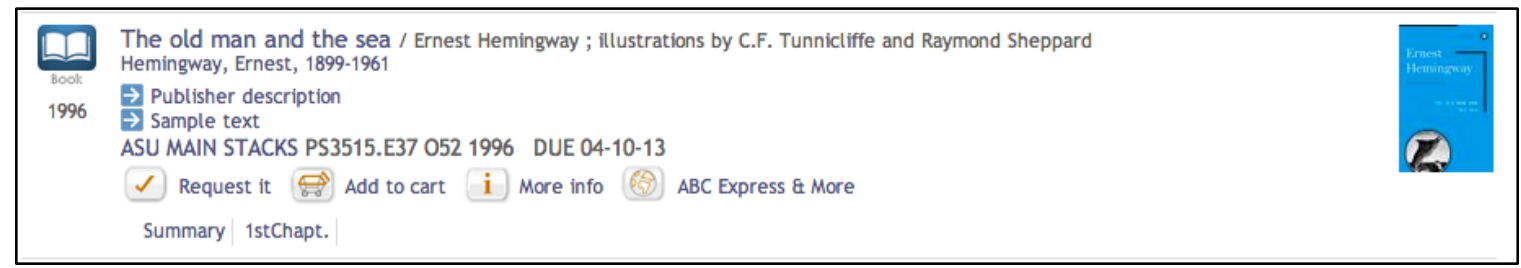

Figure 3. Detail of the screen of results for searching for "The Old Man and the Sea".

The classic catalog that most participants were familiar with has a "map it" feature (from the third party vendor StackMap), and Encore did not have that feature incorporated yet. Since this study has been completed, the "map it" has been added to the item record in APPSearch. Further research can determine if students will have a higher level of confidence in their ability to locate a book in the stacks when using Encore.

Figure 3 shows the search as it appeared in December 2012 and figure 4 has the "map it" feature implemented and pointed out with a red arrow. Related to this task of searching for a known book, student B commented that in Encore, the icons were very helpful in picking out media type.

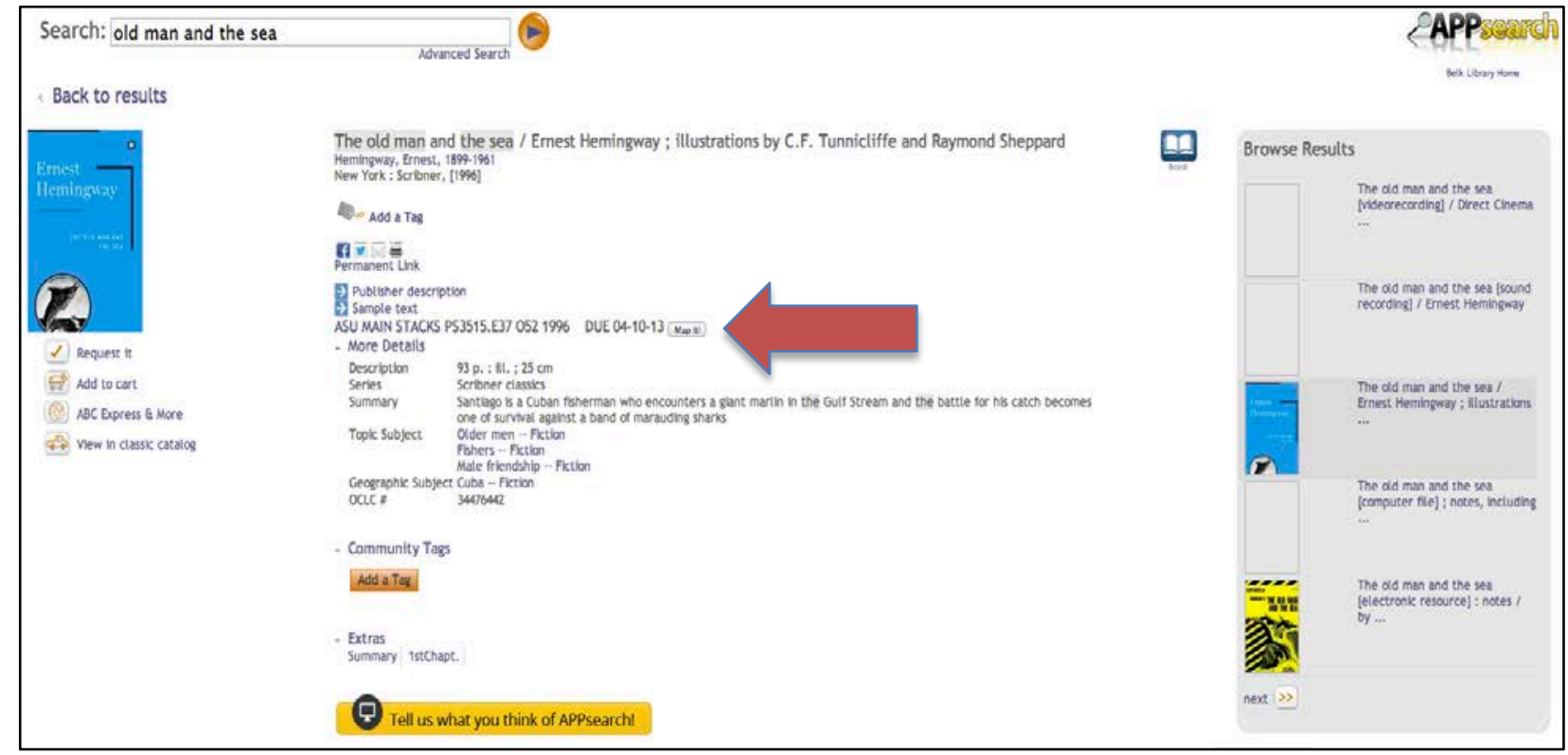

Figure 4. Book item record in Encore. The red arrow indicates the "Map it" feature, an add-on to the catalog from the vendor StackMap. Browse results are on the right, and only pull from the catalog results.

When using the tabbed layout interface (see Figure 1), three students typed the title of the book into the "articles" tab first, and it took them a few moments figure out why they had a problem with the results. They were able to figure it out and re-do the search in the "correct" Books \& 
Media tab, but student D commented, "I do that every time!" This is evidence that the average user does not closely examine a search box--they simply start typing.

\section{Task 2:}

"In your psychology class, your professor has assigned you a five-page paper on the topic of eating disorders and teens. Find a scholarly article (or peer-reviewed) that explores the relation between anorexia and self-esteem."

This question revealed, among other things, that seven out of the nine students did not fully understand the term scholarly or peer reviewed article are meant to be synonyms in this context. When asked the follow up question "what does 'peer reviewed' mean to you?" Student B said, "My peers would have rated it as good on the topic." This is the kind of feedback that librarians and vendors need to be aware of in meeting students' expectations. Users have become accustom to online ratings by their peers of hotels and restaurants, so the terminology academia uses may need to shift. Further discussion on this is in the "changes suggested" section below.

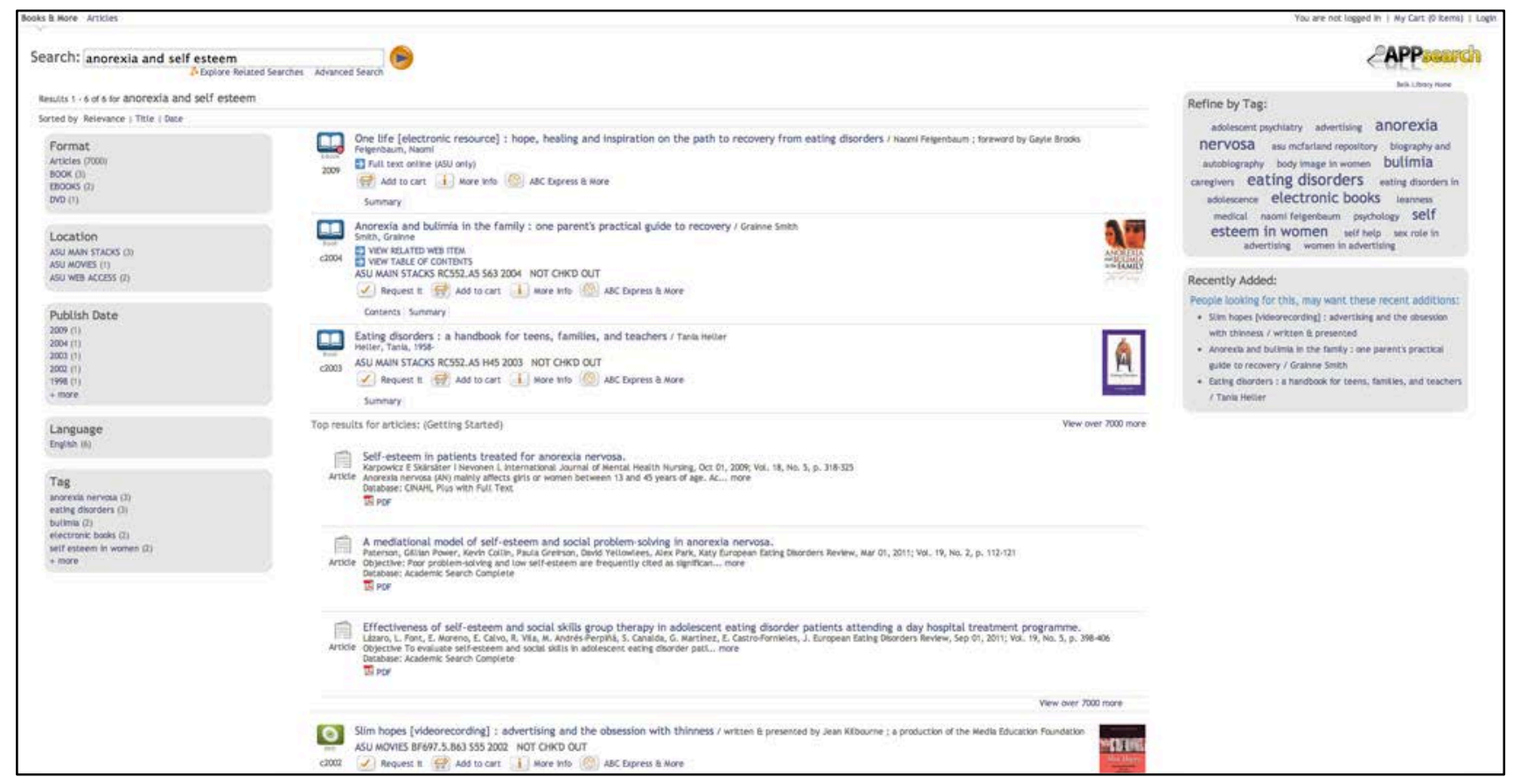

Figure 5. Typical results for task two.

Figure 5 shows a typical user result for task 2. The follow up question asked users "what does the refine by tag box on the right mean to you?" Student G reported they looked like Internet ads. Other users replied with variations of, "you can click on them to get more articles and stuff." In fact, the "refine by tag" box in the upper right column top of screen contains only indexed terms from the subject heading of the catalog. This refines the current search results to those with the specific subject term the user clicked on. In this study, no user clicked on these tags. 
For libraries considering purchasing and implementing Encore, a choice of skins is available, and it is possible to choose a skin where these boxes do not appear. In addition to information from Innovative Interfaces, libraries can check a guide maintained by a librarian at Saginaw Valley State University 17 to see examples of Encore Synergy sites, and links to how different skins (cobalt, pearl or citrus) affect appearance. Appalachian uses the "pearl" skin.

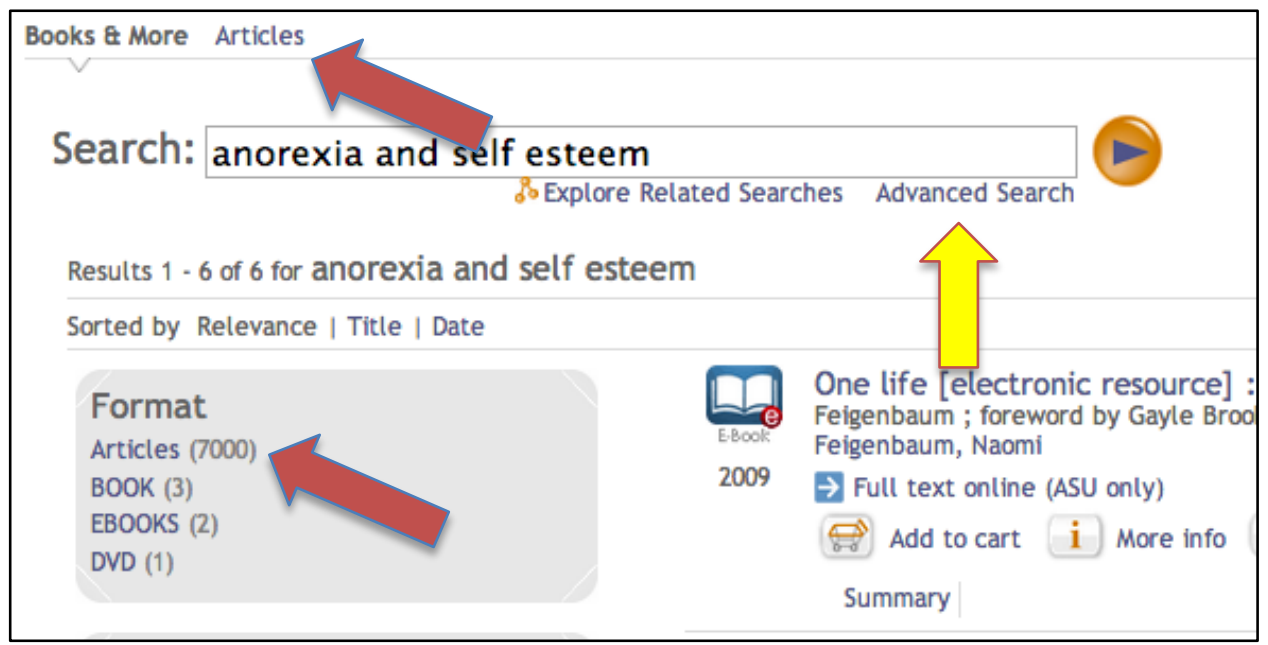

Figure 6. Detail of screenshot in Figure 5.

Figure 6 is a detail of the results shown in the screenshot for average search for task 2 . The red arrows indicate where a user can click to just see article results. The yellow arrow indicates where the advanced search button is. Six out of thirteen users clicked advanced after the initial search results. Clicking on the advanced search button brought users to a screen pictured in figure 7. 


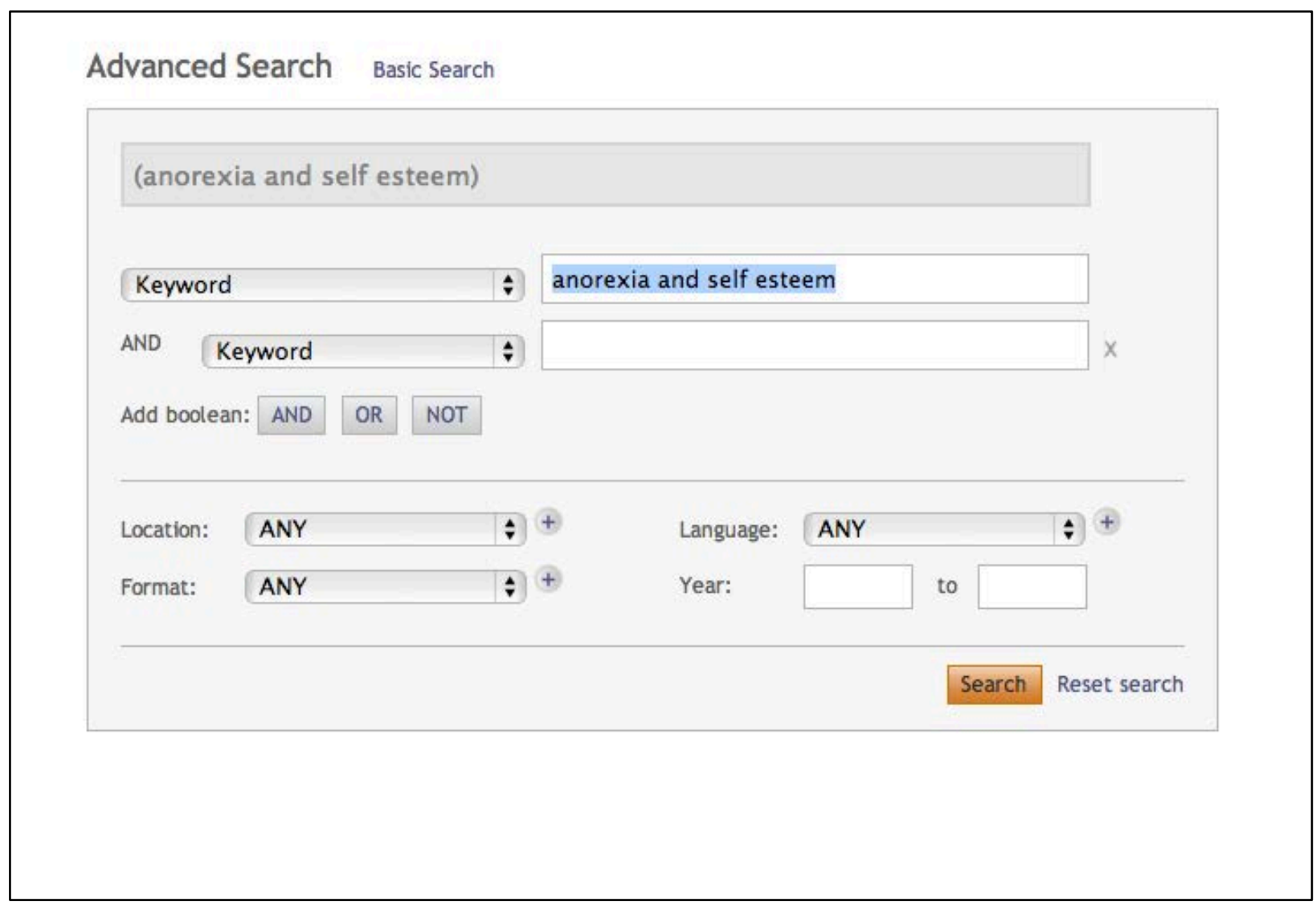

Figure 7. Encore's advanced search screen.

Figure 7 shows the Encore's advanced search screen. This search is not designed to search articles; it only searches the catalog. This aspect of advanced search was not clear to any of the participants in this study. See further discussion of this issue in the "glitches revealed" section. 


\begin{tabular}{|c|c|}
\hline \multicolumn{2}{|l|}{ Books \& More Articles } \\
\hline \multicolumn{2}{|c|}{ Search: anorexia and self esteem } \\
\hline \multicolumn{2}{|c|}{ Results 1 - 12 of 12 for anorexia and self esteem } \\
\hline \multicolumn{2}{|l|}{ Database: America: History \& Life } \\
\hline Getting Started & $\begin{array}{l}\text { The Matrix of Eating Disorder Vulnerability: Oral His } \\
\text { Leavy, Patricia Ross, Lauren Sardi }\end{array}$ \\
\hline Arts \& Humanities & $\begin{array}{l}\text { Oral History Review, Jan } 01,2006 \text {; Vol. } 33 \text {, No. } 1 \text {, p. } 65-81 \\
\text { Examines the oral history transcript of a female college student }\end{array}$ \\
\hline America: History \& Life (12) & 저 PDF \\
\hline \multirow{2}{*}{$\begin{array}{l}\text { Full Text (12) } \\
\text { Scholarly (Peer Reviewed) (9) }\end{array}$} & $\begin{array}{l}\text { The Ritual of Anorexia Nervosa in Cultural Context. } \\
\text { Journal of American Culture (01911813), Dec 01, 1991; Vol. 14, N } \\
\text { Z7 PDF }\end{array}$ \\
\hline & \\
\hline $\begin{array}{l}\text { + Subject } \\
+ \text { Publication Title }\end{array}$ & $\begin{array}{l}\text { "You even forget yourself": The Cinematic Construc } \\
\text { Wooden, Shannon R. } \\
\text { Journal of Popular Culture, Sep 01, 2002; Vol. 36, No. 2, p. 221-2 } \\
\text { đ્ PDF }\end{array}$ \\
\hline Art Full Text (13) & The Culture of Disease or the Dis-ease of Culture in \\
\hline ATLA Religion (5) & Journal of American Culture, Jun 01, 2003; Vol. 26, No. 2, p. 171 \\
\hline Film \& TV Literature (34) & 점 PDF \\
\hline Historical Abstracts with Full Text (34) & The Center Can(not) Hold: American Studies and Gld \\
\hline JSTOR (456) & $\begin{array}{l}\text { Lim, Shirley Geok-lin } \\
\text { American Studies International, Oct 01, 2000; Vol. 38, No. 3, p. }\end{array}$ \\
\hline Literature Resource Center & One global ideal of female beauty persists, wholly grounded in \\
\hline MLA & 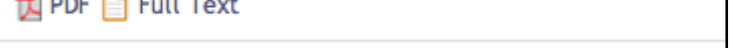 \\
\hline Phillosopher's Index & $\begin{array}{l}\text { A Network of Support: Coping with Trauma Through } \\
\text { GERAGHTY, LINCOLN }\end{array}$ \\
\hline Project Muse (42) & $\begin{array}{l}\text { Journal of Popular Culture, Dec 01, 2006; Vol. } 39 \text {, No. 6, p. } 1002 \\
\text { Provides letters written by 'Star Trek' fans to American and Brit }\end{array}$ \\
\hline Business & 짐 PDF \\
\hline Education & $\begin{array}{l}\text { The anorectic empress: Elisabeth of Austria. } \\
\text { Vandereycken, Walter van Deth, Ron }\end{array}$ \\
\hline Health & $\begin{array}{l}\text { History Today, Apr 01, 1996; Vol. 46, No. 4, p. } 12-19 \\
\text { 졍 PDF }\end{array}$ \\
\hline Newspapers & $\begin{array}{l}\text { Sporting Adam's Rib: The Culture of Women Bodybuil } \\
\text { Lewis, Cynthia }\end{array}$ \\
\hline Science - Technology - Math & $\begin{array}{l}\text { Massachusetts Review, Dec } 01,2004 \text {; Vol. } 45 \text {, No. } 4 \text {, p. } 604-631 \\
\text { Analyzes the culture of amateur and professional female bodyb }\end{array}$ \\
\hline Social Science & 저 PDF \\
\hline [All Article Databases] & $\begin{array}{l}\text { Living Dolls: The Fashion Model in Australia. } \\
\text { Maynard, Margaret }\end{array}$ \\
\hline
\end{tabular}

Figure 8. The "database portfolio" for Arts \& Humanities.

Figure 8 shows typical results for task 2 limited just to articles. The folders on the left are basically silos of grouped databases. Innovative calls this feature "database portfolios." In this screen shot, the results of the search narrowed to articles within the "database portfolio" of Arts \& Humanities. Clicking on the individual databases return results from that database, and moves the 
user to the database's native interface. For example, in Figure 8, clicking on Art Full Text would put the user into that database, and retrieve 13 results.

While conducting task 2, faculty member A stressed she felt it was very important students learn to use discipline specific databases, and stated she would not teach a "one box" approach. She felt the tabbed layout was much easier than APPSearch and rated the tabbed layout in her SUS score with a 87.5 versus the 40 she gave Encore. She also wrote on the SUS scoring sheet "APPsearch is very slow. There is too much to review." She also said that the small niche showing how to switch results between "Books \& More" to Article was "far too subtle." She recommended bold tabs, or colors. This kind of suggestion librarians can forward to the vendor, but we cannot locally tweak this layout on a development server to test if it improves the user experience.

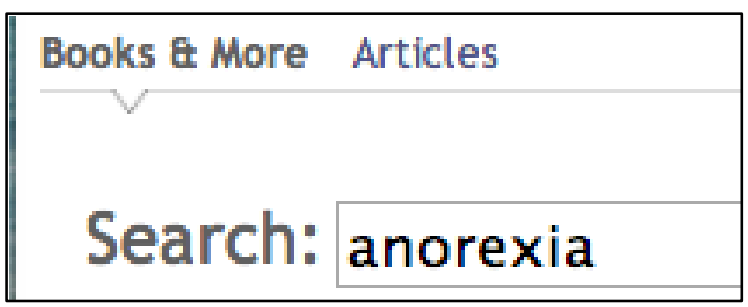

Figure 9. Closeup of switch for "Books \& More" and "Articles" options.

\section{Task 3:}

"You are studying modern Chinese history and your professor has assigned you a paper on foreign relations. Find a journal article that discusses relations between China and the US."

Most users did not have much difficulty finding an article using Encore, though three users did not immediately see a way to limit only to articles. Of the nine users who did narrow the results to articles, five used facets to further narrow results. No users moved beyond the first page of results.

Search strategy was also interesting. All thirteen users appeared to expect the search box to work like Google. If there were no results, most users went to the advanced search, and reused the same terms on different lines of the Boolean search box. Once again, no users intuitively understood that "advanced search" would not effectively search for articles. The concept of changing search terms was not a common strategy in this test group. If very few results came up, none of the users clicked on the "did you mean" or used suggestions for correction in spelling or change in terms supplied by Encore.

During this task, two faculty members commented on load time. They said students would not wait, results had to be instant. But when working with students, when the author asked how they felt when load time was slow, students almost all said it was fine, or not a problem. They could "see it was working." One student said, "Oh, I'd just flip over to Facebook and let the search run." So perhaps librarians should not assume we fully understand student user expectations. It is also 
worth noting that, for the participant, this is a low-stakes usability study, not crunch time, so attitudes may be different if load time is slow for an assignment due in a few hours.

\section{Task 4:}

"What is a topic you have written about this year? Search for materials on this topic."

This question elicited the most helpful user feedback, since participants had recently conducted research using the library's interface and could compare ease of use on a subject they were familiar with. A few specific examples follow.

Student A, in response to the task to research something she had written about this semester, looked for "elder abuse." She was a senior who had taken a research methods class and written a major paper on this topic, and she used the tabbed layout first. She was familiar with using the facets in EBSCO to narrow by date, and to limit to scholarly articles. When she was using APPsearch on the topic of elder abuse, Encore held her facets "full text" and "peer reviewed" from the previous search on China and U.S. Foreign relations. An example of Encore "holding a search" is demonstrated in figures 10 and 11 below.

Student A was not bothered by the Encore holding limits she had put on a previous search. She noticed the limits, and then went on to further narrow within the database portfolio of "health" which limited the results to the database CINAHL first. She was happy with being able to limit by folder to her discipline. She said the folders would help her sort through the results.

Student G's topic she had researched within the last semester was "occupational therapy for students with disabilities" such as cerebral palsy. She understood through experience, that it would be easiest to narrow results by searching for 'occupational therapy' and then add a specific disability. Student $\mathrm{G}$ was the user who made the most use of facets on the left. She liked Encore's use of icons for different types of materials. Student B also commented on "how easy the icons made it."

Faculty B, in looking for the a topic he had been researching recently in APPsearch, typed in "Writing Across the Curriculum glossary of terms" and got no results on this search. He said, "mmm, well that wasn't helpful, so to me, that means I'd go through here" and he clicked on the Google search box in the browser bar.

He next tried removing "glossary of terms" from his search and the load time was slow on articles, so he gave up after ten seconds and clicked on "advanced search" and tried putting "glossary of terms" in the second line. This led to another dead end. He said, "I'm just surprised Appalachian doesn't have anything on it." The author asked if he had any other ideas about how to approach finding materials on his topic from the library's homepage and he said no, he would just try Google (in other words, navigating to the group of databases for Education was not a strategy that occurred to him). 
The faculty member D had been doing research on a relatively obscure historical event and was able to find results using Encore. When asked if he had seen the articles before, he said, "Yes, I've found these, but it is great it's all in one search!"

\section{Glitches revealed}

It is of concern for the user experience that the advanced search of Encore does not search articles; it only searches the catalog. This was not clear to any participant in this study. As noted earlier, Encore's article search is a federated search. This affects load time for article results, and also puts the article results into silos, or to use Encore's terminology, "database portfolios."

Encore's information on their website definitely markets the site as a discovery tool, saying, it "integrates federated search, as well as enriched content-like first chapters-and harvested data... Encore also blends discovery with the social web. 18" It is important for libraries considering purchase of Encore that while it does have many features of a discovery service, it does not currently have a central index with pre-harvested metadata for articles.

If Innovative Interfaces is going to continue to offer an advanced search box, it needs to be made explicitly clear that the advanced search is not effective for searching for articles, or Innovative Interfaces needs to make an advanced search work with articles by creating a central index.

To cite a specific example from this study, when Student E was using AppSearch, with all the tasks, after she ran a search, she clicked on the advanced search option. The author asked her, "So if there is an advanced search, you're going to use it?" The student replied, "yeah, they are more accurate."

Another aspect of Encore that users do not intuitively grasp is that when looking at the results for an article search, the first page of results comes from a quick search of a limited number of databases (see Figure 8). The users in this study did understand that clicking on the folders will narrow by discipline, but they did not appear to grasp that the result in the database portfolios are not included in the first results shown.

When users click on an article result, they are taken to the native interface (such as Psych Info) to view the article. Users seemed un-phased when they went into a new interface, but it is doubtful they understand they are entering a subset of APPsearch. If users try to add terms or do a new search in the native database they may get relevant results, or may totally strike out, depending on chosen database's relevance to their research interest. 


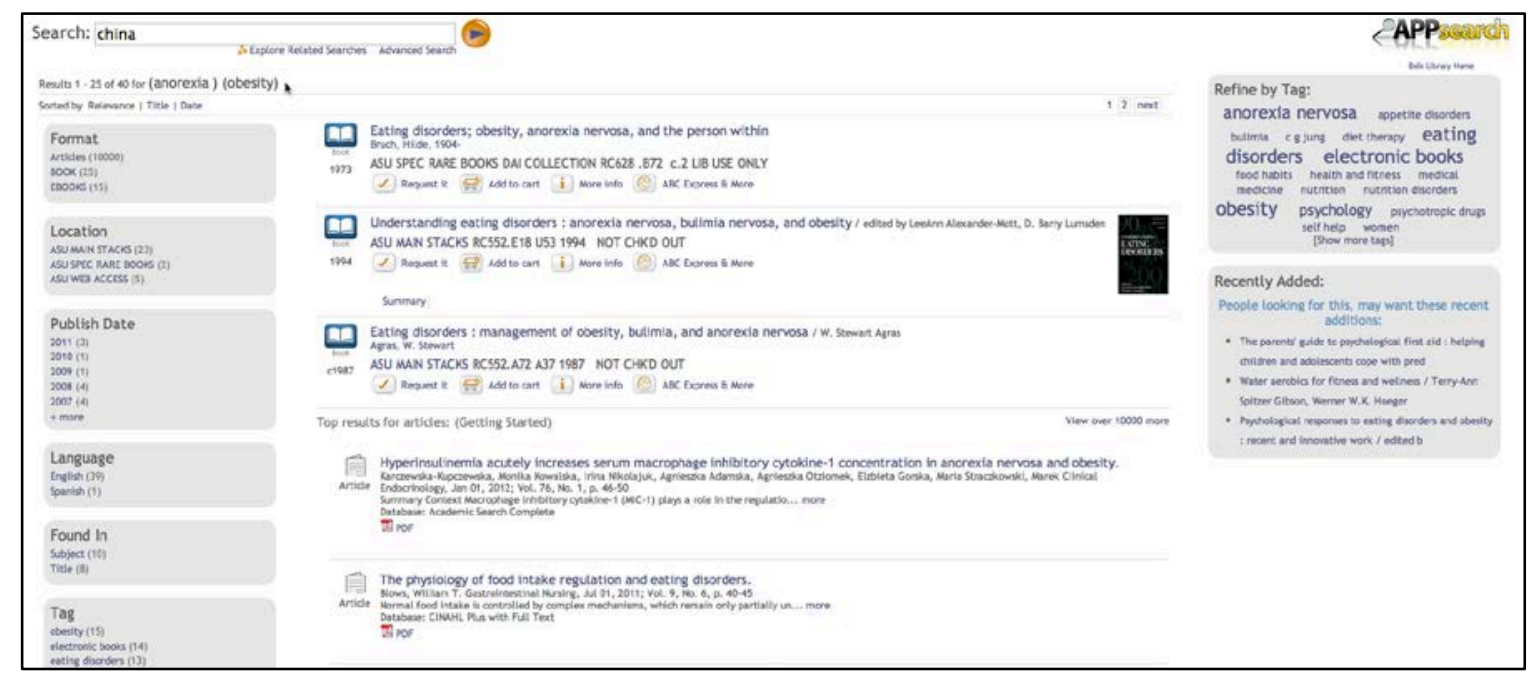

Figure 10. Changing a search in Encore.

Another problem that was documented was that after users ran a search, if they changed the text in the "Search" box, the results for articles did not change. Figure six demonstrates the results from task 2 of this study, which asks users to find information on anorexia and self-esteem. The third task asks the user to find information on China and foreign relations. Figure 10 demonstrates the results for the anorexia search, with the term "china" in the search box, just before the user clicks enter, or the orange arrow for new search.

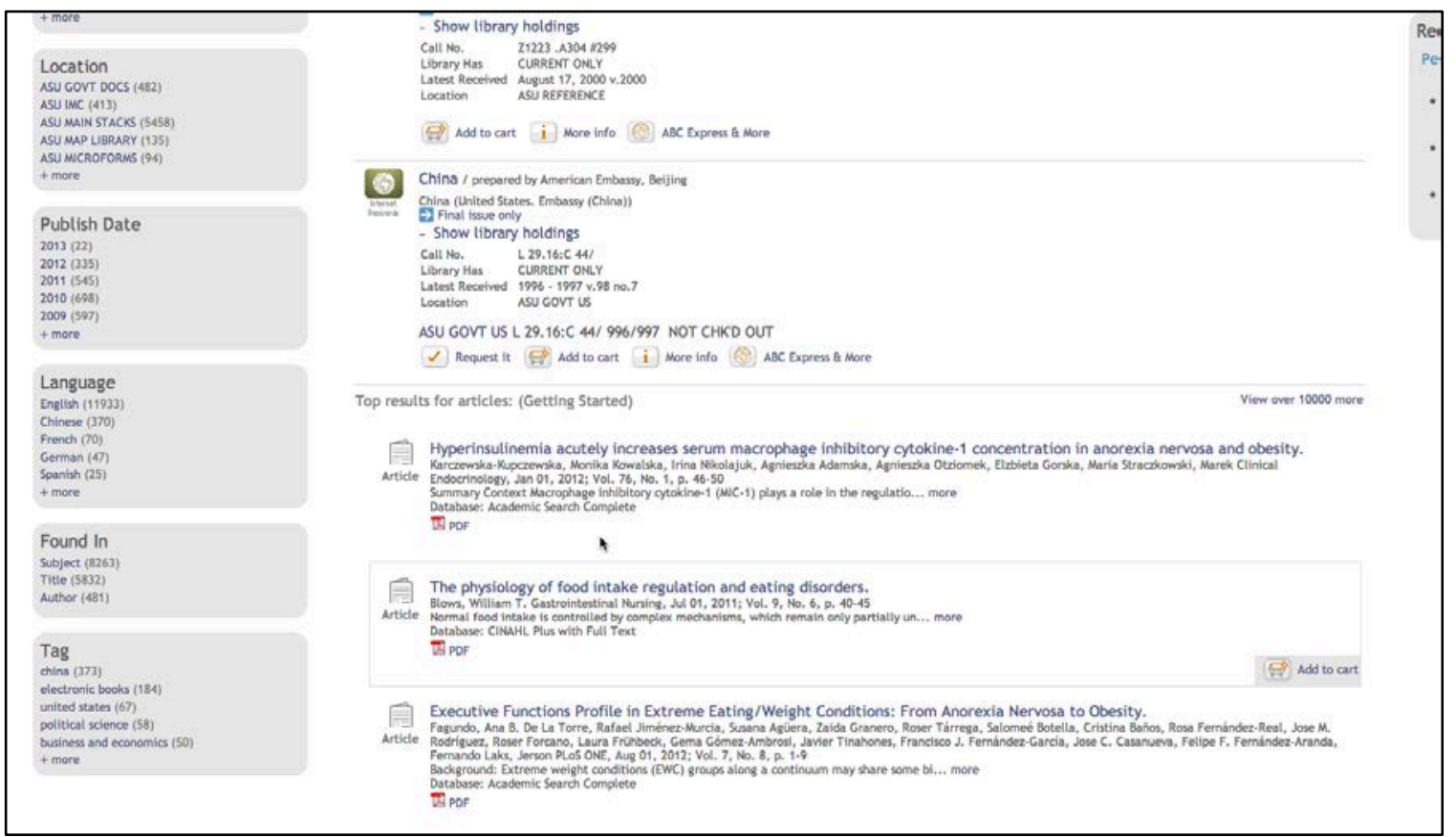

Figure 11. Search results for changed search.

Figure 11 show that the search for the new term, "China" has worked in the catalog, but the results for articles are still about anorexia. In this implementation of Encore, there is no "new search button" (except in the advanced search page, there is a "reset search" button, see Figure 7) and 
refreshing the browser is had no effect on this problem. This issue was screencast ${ }^{19}$ and sent to the vendor. Happily, as of April 2013, Innovative Interfaces appears to have resolved this underlying problem.

One purpose of this study was to determine if users had a strong preference for tabs, since the library could choose to implement Encore with tabs (one for access to articles, one for the catalog, and other tab options like Google Scholar). This study indicated users did not like tabs in general, they much preferred a "one box solution" on first encounter.

A major concern raised was the user's response to the question, "How much of the library's holdings do you think APPsearch/ Articles Quick Search is looking across?"

Twelve out of thirteen users believed that when they were searching for articles from the Quick Search for articles tabbed layout, they were searching all the library databases. The one exception to this was a faculty member in the English department, who understood that the articles tab searched a small subset of the available resources (seven EBSCO databases out of 400 databases the library subscribes to).

All thirteen users believed APPsearch (Encore) was searching "everything the library owned." The discovery service searches far more resources than other federated searches the library has had access to in the past, but it is still only searching 50 out of 400 databases.

It is interesting that in the Fagan et al. study of EBSCO's Discovery Service, only one out of ten users in that study believed the quick search would search "all" the library's resources. ${ }^{20}$ A glance at James Madison University's library homepage ${ }^{21}$ suggests wording that may improve user confusion.

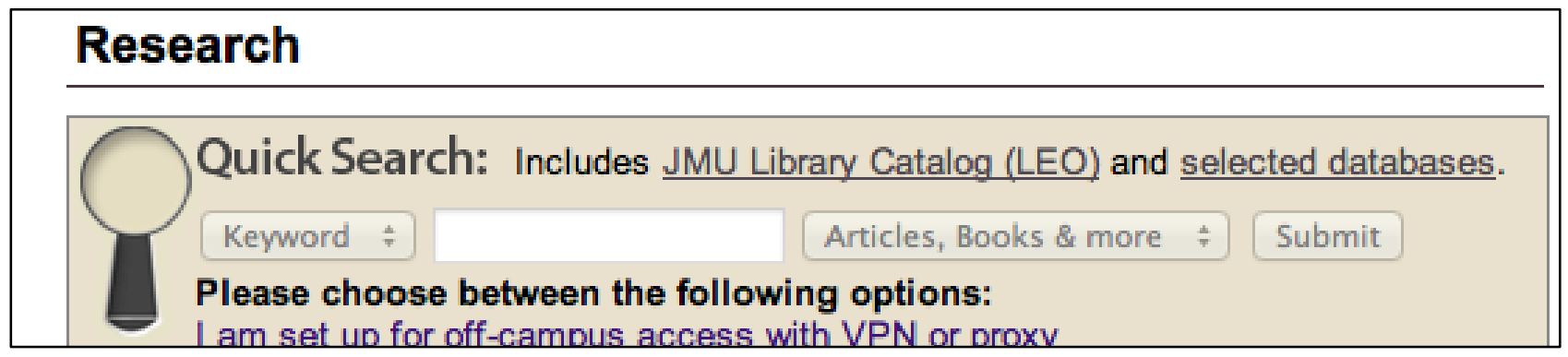

Figure 12. Screenshot of James Madison Library Homepage, accessed December 18, 2012. 


\section{APP seamch}

Search for books, journal articles, movies and more

Search

What is APPsearch? | Advanced Search Books \& More

Search: Classic Catalog | Articles Only

Figure 13. Original Encore interface as implemented in January 2013.

Given the results that $100 \%$ of the users believed that APPsearch looked at all databases the library has access to, the library made changes to the wording in the search box. (See figure 7). Future tests can determine if this has any positive effect on the understanding of what APPsearch includes.

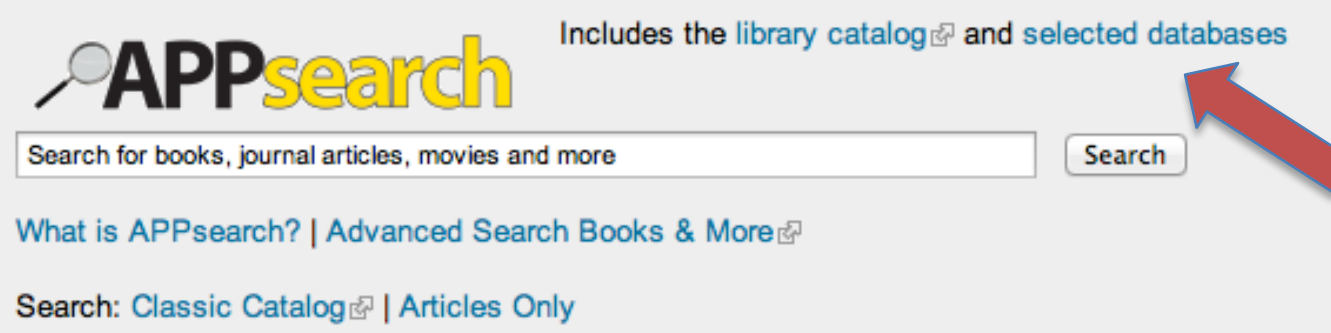

Figure 14. Encore search box after this usability study was completed. The arrow highlights additions to the page as a result of this study.

Some other wording changes suggested were from the finding that only seven out of nine students fully understood that "peer reviewed" would limit to scholarly articles. A suggestion was made to Innovative Interfaces to change the wording to "Scholarly (Peer Reviewed)" and they did so in early January. Although Innovative's response on this issue was swift, and may help students, changing the wording does not address the underlying information literacy issue of what students understand about these terms.

Interestingly, Encore does not include any "help" pages. Appalachian's liaison with Encore has asked about this and been told by Encore tech support that Innovative feels the product is so intuitive; users will not need any help. Belk Library has developed a short video tutorial for users, and local help pages are available from the library's homepage, but according to Innovative, a link to these resources cannot be added to the top right area of the Encore screen (where help is commonly located in web interfaces). Although it is acknowledged that few users actually read "help" pages, it seems like a leap of faith to think a motivated searcher will understand things like the "database portfolios" (see Figures 9) without any instruction at all. After implementation, the 
librarians here at Appalachian conducted internally developed training for instructors teaching APPsearch, and all agreed that understanding what is being searched and how to best perform a task such as an advanced article search is not "totally intuitive," even for librarians.

Finally, some interesting search strategy patterns were revealed. On the second and third questions in the script (both having to do with finding articles) five of the thirteen participants had the strategy of putting in one term, then after the search ran, adding terms to narrow results using the advanced search box. Although this is a small sample set, it was a common enough search strategy to make the author believe this is not an unusual approach. It is important for librarians and for vendors to understand how users approach search interfaces so we can meet expectations.

\section{Further Research}

The findings of this study suggest librarians will need to continue to work with vendors to improve discovery interfaces to meet users expectations. The context of what is being searched and when is not clear to beginning users in Encore

One aspect of this test was it was the participants' first encounter with a new interface, and even Student D, who was unenthused about the new interface (she called the results page "messy, and her SUS score was 37.5 for Encore, versus 92 for the tabbed layout) said that she could learn to use the system given time. Further usability tests can include users who have had time to explore the new system.

Specific tasks that will be of interest in follow up studies of this report are if students have better luck in being able to know where to find the item in the stacks with the addition of the "map it" feature. Locally, librarian perception is that part of the problem with this results display is simply visual spacing. The call number is not set apart or spaced so that it stands out as important information (see figure 5 for a screenshot).

Another question to follow up on will be to repeat the question, "How much of the library's holdings do you think APPsearch is looking across?" All thirteen users in this study believed APPsearch was searching "everything the library owned." Based on this finding, the library made small adjustments to the initial search box (see figures 14 and 15 as illustration). It will be of interest to measure if this tweak has any impact.

\section{SUMMARY}

All users in this study recommended that the library move to Encore's "one box" discovery service instead of using a tabbed layout. Helping users figure out when they should move to using discipline specific databases will most likely be a long-term challenge for Belk Library, and for other academic libraries using discovery services, but this will probably trouble librarians more than our users. 
The most important change Innovative Interfaces could make to their discovery service is to create a central index for articles, which would improve load time and allow for an advanced search feature for articles to work efficiently.

Because of this study, Innovative Interfaces made a wording change in search results for article to include the word "scholarly" when describing peer reviewed journal articles in Belk Library's local implementation. Appalachian State University libraries will continue to conduct usability studies and tailor instruction and e-learning resources to help users navigate Encore and other library resources.

Overall, it is expected users, especially freshman and sophomores, will like the new interface but will not be able to figure out how to improve search results, particularly for articles. Belk Library \& Information Commons' instruction team is working on help pages and tutorials, and will incorporate the use of Encore into the library's curricula.

\section{REFERENCES}

1. Thomsett-Scott, Beth, and Patricia E. Reese. "Academic Libraries and Discovery Tools: A Survey of the Literature." College \& Undergraduate Libraries 19 (2012): 123-43.

2. Ibid, 138.

3. Hunter, Athena. "The Ins and Outs of Evaluating Web-Scale Discovery Services" Computers in Libraries 32, no. 3 (2012) http://www.infotoday.com/cilmag/apr12/Hoeppner-Web-ScaleDiscovery-Services.shtml (accessed March 18, 2013)

4. Fagan, Jody Condit, Meris Mandernach, Carl S. Nelson, Jonathan R. Paulo, and Grover Saunders. "Usability Test Results for a Discovery Tool in an Academic Library." Information Technology \& Libraries 31, no. 1 (2012): 83-112.

5. Thomas, Bob., and Buck, Stephanie. OCLC's WorldCat local versus III's WebPAC. Library Hi Tech, 28(4) (2010), 648-671. doi: http://dx.doi.org/10.1108/07378831011096295

6. $\quad$ Becher, Melissa, and Kari Schmidt. "Taking Discovery Systems for a Test Drive." Journal Of Web Librarianship 5, no. 3: 199-219 [2011]. Library, Information Science \& Technology Abstracts with Full Text, EBSCOhost (accessed March 17, 2013).

7. Ibid, p. 202

8. Ibid p. 203

9. Allison, Dee Ann, "Information Portals: The Next Generation Catalog," Journal of Web Librarianship 4, no. 1 (2010): 375-89, http://digitalcommons.unl.edu/cgi/viewcontent.cgi?article=1240\&context=libraryscience (accessed March 17, 2013) 
10. Singley, Emily. 2011 “Encore Synergy 4.1: A review” The cloudy librarian: musings about library technologies http://emilysingley.wordpress.com/2011/09/17/encore-synergy-4-1-areview/ [accessed March 20, 2013].

11. Nielson, Jakob. 2000. "Why You Only Need to Test with 5 Users" http://www.useit.com/alertbox/20000319.html (accessed December 18, 2012].

12. Fagan et al, 90 .

13. Dixon, Lydia, Cheri Duncan, Jody Condit Fagan, Meris Mandernach, and Stefanie E. Warlick. 2010. "Finding Articles and Journals via Google Scholar, Journal Portals, and Link Resolvers: Usability Study Results." Reference \& User Services Quarterly no. 50 (2):170-181.

14. Bangor, Aaron, Philip T. Kortum, and James T. Miller. 2008. "An Empirical Evaluation of the System Usability Scale." International Journal of Human-Computer Interaction no. 24 (6):574-594. doi: 10.1080/10447310802205776.

15. Sauro, Jeff. 2011. "Measuring Usability With the System Usability Scale (SUS)” http://www.measuringusability.com/sus.php. [accessed December 7, 2012].

16. Ibid.

17. Mellendorf, Scott. "Encore Synergy Sites" Zahnow Library, Saginaw Valley State University. http://librarysubjectguides.svsu.edu/content.php?pid=211211 (accessed March 23, 2013).

18. Encore overview, “http://encoreforlibraries.com/overview/” (accessed March 21, 2013).

19. Johnson, Megan. Videorecording made with Jing on January 30, 2013 http://www.screencast.com/users/Megsjohnson/folders/Jing/media/0ef8f186-47da-41cf$\underline{96 \mathrm{cb}-26920 \mathrm{f} 71014 \mathrm{~b}}$

20. Fagan et al. 91.

21. James Madison University Libraries, “http://www.lib.jmu.edu” (accessed December 18, 2012). 


\section{APPENDIX A}

\section{Pre-Purchase Usability Benchmarking Test}

In April 2012, before the library purchased Encore, the library conducted a small usability study to serve as a benchmark. The study outlined in this paper follows the same basic outline, and adds a few questions.

The purpose of the April study was to measure student perceived success and satisfaction with the current search system of books and articles Appalachian uses compared with use of the implementation of Encore discovery services at University of Nebraska Lincoln (UNL).

The methodology was four undergraduates completing a set of tasks using each system. Two started with UNL, and two started at Appalachian's library homepage.

In the April 2012 study, the participants were three freshman and one junior, and all were female. All were student employees in the library's mailroom, and none had received special training on how to use the library interface.

After the students completed the tasks, they rated their experience using the System Usability Scale (SUS). In the summary conclusion of that study, the average SUS score for the library's current search box layout was 62, and for UNL's Encore search it was 49. Even though none of the students was particularly familiar with the current library's interface, it might be assumed that part of the higher score for Appalachian's site was simply familiarity.

Student comments from the small April benchmarking study included the following. The junior student said the UNL site had "too much going on" and Appalachian was "easier to use; more specific in my searches, not as confusing as compared to UNL site." Another student (a freshman), said she has "never used the library not knowing if she needed a book or an article." In other words, she knows what format she is searching for and doesn't perceive a big benefit to having them grouped. This same student also indicated she had no real preference between Appalachian or the UNL. She believed students would need to take time to learn either and that UNL is a "good starting place." 


\section{APPENDIX B}

\section{Instructions for Conducting the Test}

Notes: Use Firefox for the browser, set to "private browsing" so that no searches are held in the cache (search terms to not pop into the search box from the last subject's search). In the bookmark toolbar, the only two tabs should be available "dev" (which goes to the development server) and "lib" (which goes to the library's homepage). Instruct users to begin each search from the correct starting place. Identify students and faculty by letter (Student A, Faculty A, etc).

\section{Script}

$H i$ My name is , and I'm going to be walking you through this session today.

Before we begin, I have some information for you, and I'm going to read it to make sure that I cover everything. You probably already have a good idea of why we asked you here, but let me go over it again briefly. We're asking students and faculty to try using our library's home page to conduct four searches, and then ask you a few other questions. We will then have you do the same searches on a new interface.

(Note: half the participants to start at the development site, the other half start at current site). After each set of tasks is finished, you will fill out a standard usability scale to rate your experience. This session should take about twenty minutes.

The first thing I want to make clear is that we're testing the interface, not you. You can't do anything wrong here.

Do you have any questions so far?

OK. Before we look at the site, I'd like to ask you just a few quick questions.

What year are you in college?

What are you majoring in?

Roughly how many hours a week altogether--just a ballpark estimate--would you say you spend using the library website?

OK, great.

Hand the user the task sheet. Do not read the instructions to the participant, allow them to read the directions for themselves. Allow the user to proceed until they hit a wall or become frustrated. Verbally encourage them to talk aloud about their experience. 


\section{Written instructions for participants.}

Find the a copy of the book the Old Man and the Sea.

In your psychology class, your professor has assigned you a 5-page paper on the topic of eating disorders and teens. Find a scholarly article (or peer-reviewed) that explores the relation between anorexia and self-esteem.

You are studying modern Chinese history and your professor has assigned you a paper on foreign relations. Find a journal article that discusses relations between China and the US.

What is a topic you have written about this year? Search for materials on this topic. 


\section{APPENDIX C}

\section{Follow up Questions for Participants}

(Or ask as the subject is working)

After the first task (find a copy of the book The Old Man and the Sea) when the user finds the book in APPSearch, ask "Would you know where to find this book in the library?"

How much of the library's holdings do you think APPSearch/ Articles Quick Search is looking across?

Does "Peer Reviewed" mean the same as "scholarly article"?

What does the "refine by tag" block the right mean to you?

If you had to advise the library to either stay with a tabbed layout, or move to the one search box, what would you recommend?

Do you have any questions for me, now that we're done?

Thank subject for participating. 
APPENDIX D

Sample System Usability Scale (SUS)

\begin{tabular}{|c|c|c|c|c|c|}
\hline \multirow{3}{*}{\begin{tabular}{|l|} 
\\
I think that I would like to use this system \\
frequently
\end{tabular}} & \multicolumn{4}{|c|}{$\begin{array}{l}\text { Strongly } \\
\text { disagree }\end{array}$} & \multirow{3}{*}{$\begin{array}{l}\text { Strongly } \\
\text { agree }\end{array}$} \\
\hline & & & & & \\
\hline & 1 & 2 & 3 & 4 & \\
\hline \multirow{2}{*}{ I found the system unnecessarily complex } & & & & & \\
\hline & 1 & 2 & 3 & 4 & 5 \\
\hline \multirow{2}{*}{ I thought the system was easy to use } & & & & & \\
\hline & 1 & 2 & 3 & 4 & 5 \\
\hline \multirow{2}{*}{$\begin{array}{l}\text { I think that I would need the support of a } \\
\text { technical person to be able to use this } \\
\text { system }\end{array}$} & & & & & \\
\hline & 1 & 2 & 3 & 4 & 5 \\
\hline \multirow{2}{*}{$\begin{array}{l}\text { I found the various functions in this system } \\
\text { were well integrated }\end{array}$} & & & & & \\
\hline & 1 & 2 & 3 & 4 & 5 \\
\hline \multirow{2}{*}{$\begin{array}{l}\text { I thought there was too much } \\
\text { inconsistency in this system }\end{array}$} & & & & & \\
\hline & 1 & 2 & 3 & 4 & 5 \\
\hline \multirow{2}{*}{$\begin{array}{l}\text { I would imagine that most people would } \\
\text { learn to use this system very quickly }\end{array}$} & & & & & \\
\hline & 1 & 2 & 3 & 4 & 5 \\
\hline \multirow{2}{*}{$\begin{array}{l}\text { I found the system very cumbersome to } \\
\text { use }\end{array}$} & & & & & \\
\hline & 1 & 2 & 3 & 4 & 5 \\
\hline \multirow{2}{*}{ I felt very confident using the system } & & & & & \\
\hline & 1 & 2 & 3 & 4 & 5 \\
\hline \multirow{2}{*}{$\begin{array}{l}\text { I needed to learn a lot of things before I } \\
\text { could get going with this system }\end{array}$} & & & & & \\
\hline & 1 & 2 & 3 & 4 & 5 \\
\hline
\end{tabular}

Comments: 